\title{
A Woman with Mild Pain in the Right Upper Quadrant
}

Ural Koç

Deparment of Radiology, Kırıkkale University School of Medicine, Kırıkkale, Turkey

A 69-year-old woman presented to the emergency department (ED) with mild pain in the right upper quadrant. She had a history of similar pain intermittently, but she did not visit the doctor regarding this, until she presented to the ED. Laboratory tests showed that her transaminase and total bilurubin levels were within normal limits. A physical examination revealed an absence of Murphy's sign. Transabdominal sonography revealed the following: multiple septa with a honeycomb appearance at the fundus of the gallbladder, the presence of gallstones in the body, and sludge in multiple septa (Figure 1).

Biliary tract anomalies can be seen in approximately $10 \%$ of humans; in such anomalies, the most common variation related to the gallbladder is locational differences $(1,2)$. Gallbladder agenesis and duplication are rare. A multiseptate gallbladder is a rare congenital malformation of the gallbladder, which is characterised by the bridging of multiple septa in a honeycomb pattern within the gallbladder lumen (2). Multiple septa can lead to bile stasis, thereby influencing bile motility $(2,3)$. Due to stasis and ineffective motility, cholecystitis and cholelithiasis may occur. On the one hand, asymptomatic patients can get incidentally diagnosed when getting imaged for other reasons; on the other hand, chronic or intermittent gallbladder colic pain may clinically occur because of stasis or cholelithiasis. A multiseptate gallbladder can be associated with hepatobiliary and pancreatic ductal anomalies and can also increase the risk of cancer (4). Ultrasound is an important diagnostic workup tool for detecting a multiseptate gallbladder at the initial stage; magnetic resonance cholangiopancreatography and other imaging modalities can be selectively used for diagnoses (5). Symptomatic patients can be treated by cholecystectomy. At first glance, patients who are independent of biliary symptoms may not need surgical treatment; however, they should be closely followed up.

\section{References}

1. Mentzer SH. Anomalous bile ducts in man, based on a study of comparative anatomy. JAMA 1929; 93: 1273-7. [CrossRef]

2. Kapoor V, Federie MP, Peterson MS, Coll DA. Long term sonographic follow-up of stable imaging findings of multiseptate gallbladder. JUM 2002; 21: 677-80.

3. Karaca T, Yoldas O, Bilgin BC, Bilgin S, Evcik E, Ozen S. Diagnosis and treatment of multiseptate gallbladder with recurrent abdominal pain. Case Rep Med 2011: 162853.

4. Ono S, Sakai K, Kimura O, Iwai N. Development of bile duct cancer in a 26-year-old man after resection of infantile choledochal cyst. J Pediatr Surg 2008; 43: 17-9. [CrossRef]

5. Nakazawa T, Ohara H, Sano H. Multiseptate gallbladder: diagnostic value of MR cholangiography and ultrasonography. Abdom Imaging 2004; 29:691-3. [CrossRef]

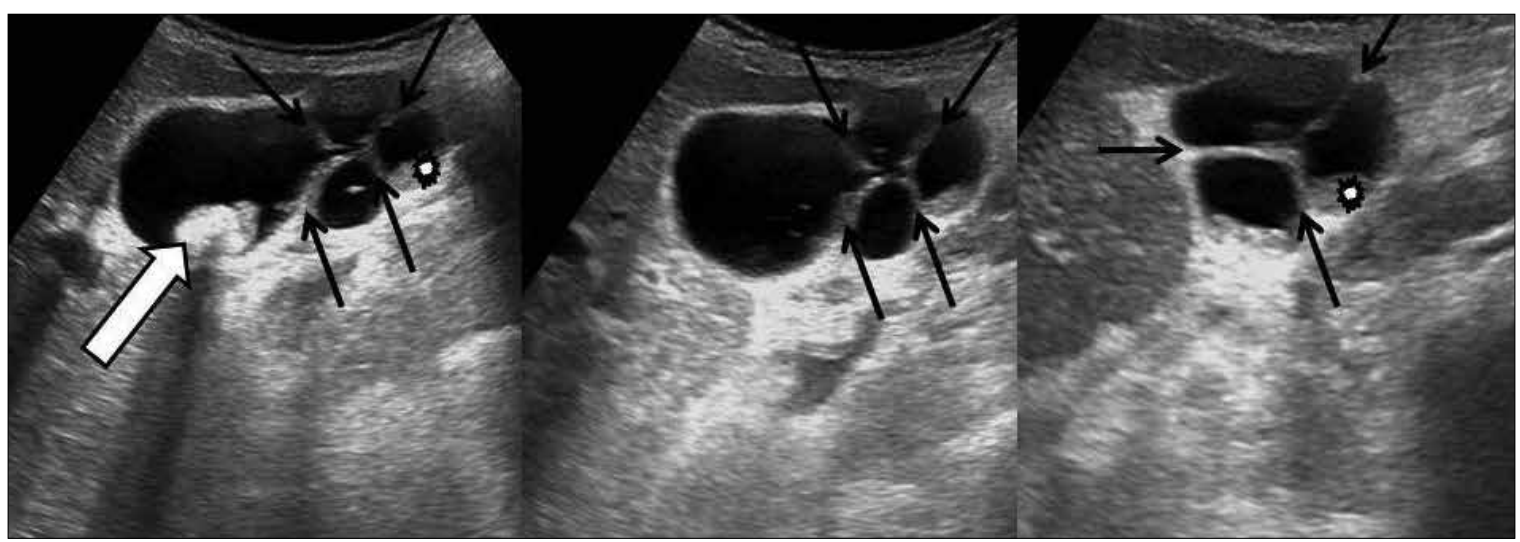

Figure 1. Transabdominal sonography showed multiple septa with a honeycomb appearance (black arrows), gallstones (wide arrow), and sludge (star shape) within the honeycomb appearance

Correspondence to: Ural Koç e-mail: dr_uralkoc@hotmail.com 